\title{
Controlling Research Activity of Students by Digital Tools
}

\author{
Sergey Likhachev ${ }^{1 *}$, Tatyana Likhacheva ${ }^{1}$, Lyudmila Silchenkova ${ }^{1}$, Elvira Krivorotova $^{1}$, \\ and Lukas Plesnik ${ }^{2}$ \\ ${ }^{1}$ Moscow City University, Moscow, Russia \\ ${ }^{2}$ University of Ostrava, Ostrava, Czech Republic
}

\begin{abstract}
This article discusses the issue of control of creative research work of students under conditions of involuntary distant communication. The aim of this article is to establish interconnection between implementation of the most recent special content and software into learning process and willingness of students for distant research work. It is assumed that a necessary condition for solution to this problem is the optimal assisted and integrated usage of digital resources and programs. This assumption has been verified by the following methods: pedagogical experiment including conversation, consultation and remote graphical support of student activities, sociological questionnaire survey, and parametric analysis of results of student research work. The experimental procedure was comprised of four installed programs, four types of network service, and three content resources. The obtained results demonstrate that the willingness of students to complete research work in a competent manner significantly increased. Another result is that research works of students corresponded to most criteria, except for the requirement of statistic data processing.
\end{abstract}

\section{Introduction}

In the situation of necessary distance learning under conditions of self-isolation, the new digital tools [1] to control student research works [2] become highly important. This can be attributed to unavailability of personal contact, paper resources of conventional libraries, hand-written proofreading, participation of students in face-to-face meetings, invitation of students to attend administration, etc. Therefore, it can be stated that possibilities for repressive control are significantly reduced. In addition, certain opportunities arise to control emotionally research works $(\mathrm{R} \& \mathrm{D})$ of students by creating interest to the work related with digitalization of scientific activities.

There appeared contradiction between impossibility to apply conventional methods to control R\&D of students and necessity to continue such work under conditions of distant communications up to achievement of result: development and defense of graduate qualification thesis (GQT). The formulated contradiction serves as a basis for further assumption: upon reduction of conventional tools to control R\&D of students, the creation of GQT meeting the requirements to originality and scientific content is possible in the frames

\footnotetext{
*Corresponding author: likhachevsv@mgpu.ru
} 
of distant communication, provided that certain conditions are fulfilled. 1) Orientation of student to success [3, pp. 104] by democratizing communications and increase in efficiency of R\&D by electronic access to consultations, experimental R\&D base and publications [4]. 2) Qualified access to digital tools: libraries, search systems, text and spreadsheet editors, survey and testing tools, digital educational mediums, systems of translation and statistic data processing [5, pp. 140]. 3) Consultative support of student while using the aforementioned resources for R\&D by supervisor in the mode of synchronous support [6, pp. 101]. 4) Integration of the aforementioned tools [7].

Pedagogy defines educational standards $[8, \mathrm{pp} .85,9,10]$, which assume control of creativity and R\&D of students, including upon formation of informational and communicative competence. In order to control R\&D of students, it is required to determine their capabilities, cleverness [11]. It is necessary to motivate them to create GQT as a planned project. "The university teacher using design technology should be able: to create motivation for qualitative realization of the project by students; create the educational atmosphere as close as possible to the future professional work" [12, pp. 582-583]. Herewith, it is recommended to apply interactive technologies: "In the active and interactive learning, the student to a greater extent becomes a subject of educational activity, enters into dialogue with the teacher" [13, pp. 6558, 14], which are required not by themselves. "What is the need to master students, is it only universal learning activities, or is everything much more complicated?" [15, pp. 26]. This question leads to necessity to apply these technologies for solution to vitally important problems: "It should be noted that the wording of some learning outcomes already implies the pragmatically oriented, goal-centered educational focus" [16, pp. 240]. We should progress in this way from basics to professionalism, since "Teacher creates a surrounding subjective educational field" [17, pp. 30].

\section{Methods}

Required tools:

A. Hardware. PC, access terminal at the rate of at least $100 \mathrm{Mb}$, smartphone [18].

B. Installed software: Windows, Word, Excel, Teams.

C. Online software. Google-forms, search systems, Deepl e-translation system and automatic system of statistic data processing (automatic calculation of Student's t-test) [19].

D. Online resources. E-Library, Moscow Electronic School, Antiplagiat: software to detect plagiarism.

Selection of software was based on three criteria: availability either on MGPU site or in free access; functional capabilities; reliability.

Willingness of student to successful completion of research work, creation of GQT, was evaluated by questionnaire, developed and published in Google-forms: Self-assessment of success of student research, filled before and after experiments.

1. Assess your willingness to carry out distant surveys and testing in the frames of pregraduation practice.

2. Assess your willingness to conduct lesson in the frames of pre-graduation practice.

3. Assess your willingness to provide valid experimental conditions upon distant realization.

4. Do you think it is possible to select and to analyze scientific publications remotely with reasonable consumptions of labor and time?

5. Are you ready to provide usage of publications for recent five years in the required scope?

6. Are you ready to provide usage of foreign publications in the required scope?

7. Are you to provide independently the structure and format of scientific text?

8. Are you ready to provide statistic data processing for completion of GQT? 
9. Can you write text complying with the requirements of originality without difficulties?

10. Can you independently understand an English article while searching for scientific information?

Variants of answer to each question: yes, no, don't know.

\section{Content of experimental work}

32 students of graduate courses of Institute of pedagogy and psychology of education, MGPU, participated in the experiments.

Main communications with the students were carried out using MS Teams: consultations were made in MS Teams with demonstration of remote reference work by supervisor, this was aided by creation of specialized channels allowing to consult several students at once. The supervisor work was demonstrated by Share option. Consultations were performed with demonstration of the following options.

1. Conduction of lessons using MES. Selection of atomic content (texts, assignments, illustrations), addition of materials, lesson preview, distribution of material to dialogue desktop, teacher tablet, student tablet), layout of lesson scenario, creation and usage of interactive materials and tests.

2. Surveying in Google-forms. Features of questionnaire formulations, filling, sending.

3. Working with E-Library. Synchronous assistance in registration of students in the library (with demonstration of student screen to the teacher), using options of expanded search by publication type, by novelty, access to open texts, arrangement of citation and correct reference.

4. MS Word: editing "Header", "Default", "Content" styles; creation and updating of electronic content; creation and processing of methodologically correct table with two inputs; technical formatting and proofreading of scientific test using Autocorrect option.

5. MS Excel. Creation of plots and bar diagrams with accounting for amount of variables, correct data position on abscissa and ordinate.

6. Using Deepl artificial intelligence tools to optimize and edit scientific data in foreign publications.

7. Psychol-ok resource (automatic calculation of Student's t-test) with consideration for necessity to select scale of intervals and ratios, calculations for the case with independent or dependent selections.

8. Antiplagiat system, in particular, database connection, paraphrasing option, preview of full text of the obtained results.

MS Teams was also used by students for preview of recorded consultations and demonstration of student works to teacher with parallel oral control by the teacher.

\section{Results}

The results were converted into percent using Google-forms and are summarized in Table 1.

Table 1. Comparison of self-assessment of success of student research before and after experimental work

\begin{tabular}{|c|c|c|c|c|c|c|}
\hline \multirow{2}{*}{ No. Variant } & \multicolumn{3}{|c|}{$\begin{array}{l}\text { Before start of experimental work, } \\
\%\end{array}$} & \multicolumn{3}{|c|}{$\begin{array}{l}\text { After completion of experimental } \\
\text { work, } \%\end{array}$} \\
\hline & yes & no & don't know & yes & no & don't know \\
\hline 1 & 59 & 9 & 32 & 84 & 6 & 10 \\
\hline 2 & 59 & 28 & 13 & 88 & 3 & 9 \\
\hline 3 & 56 & 13 & 31 & 47 & 13 & 40 \\
\hline 4 & 88 & 3 & 9 & 97 & 0 & 3 \\
\hline
\end{tabular}




\begin{tabular}{|c|c|c|c|c|c|c|}
\hline 5 & 66 & 9 & 25 & 84 & 6 & 6 \\
\hline 6 & 25 & 47 & 28 & 25 & 31 & 44 \\
\hline 7 & 66 & 9 & 25 & 88 & 6 & 6 \\
\hline 8 & 66 & 9 & 25 & 69 & 3 & 28 \\
\hline 9 & 56 & 13 & 31 & 60 & 15 & 25 \\
\hline 10 & 25 & 66 & 9 & 25 & 66 & 9 \\
\hline
\end{tabular}

In addition to survey, the experimental results were estimated also using assessment of GQT text by the time of preliminary defense presented in Table 2.

Table 2. Assessment of GQT text by the time of preliminary defense

\begin{tabular}{|l|c|c|}
\hline \multicolumn{1}{|c|}{ Parameter } & $\mathbf{+ , \%}$ & $\mathbf{- , ~ \%}$ \\
\hline Correct experimental learning & 90 & 10 \\
\hline Data acquisition regarding results of experimental learning & 90 & 10 \\
\hline Correct arrangement of references and citations & 80 & 20 \\
\hline Functionally applicable formatting of research e-text & 80 & 20 \\
\hline Correct arrangement of infographics & 80 & 20 \\
\hline Required number of references in foreign language and their citation & 90 & 10 \\
\hline Norms of originality, \% & 90 & 10 \\
\hline Reliable results of statistic data processing & 50 & 50 \\
\hline
\end{tabular}

\section{Discussion}

Before start of the experimental work most of the students were not ready to complete GQT with consideration for necessity to carry out experiment and to work with text remotely. One of the most frequently asked questions was the question of possible presentation of the thesis in previously prepared form due to the self-isolation mode, i.e. without completed experimental section and with certain fault regarding other parameters. Due to opportunities to receive consultations when necessary, sometimes shortly, to review the consultations repeatedly, i.e. to avoid time consumptions for travelling and labor consumptions for recording the advice, positive emotional background was created. Since opportunities of education e-tools, as well as speech control in these programs upon demonstration of screen by student to teacher were visually illustrated, the student obtained possibility to solve most of the occurring problems, which was confirmed by surveying results and parametric assessment of GQT in Tables 1 and 2.

\section{Conclusion}

The performed experimental work makes it possible to conclude that interactive acquaintance of students with specialized software and resources for R\&D together with synchronous support by supervisor in distant format made it possible to create orientation of student to success and provided possibility to prepare GQT meeting most of the requirements in terms of parameters summarized in Table 2. Willingness of students to complete research work in a competent manner increased significantly, which could be attributed to implementation of advanced digital tools into learning process.

Another result is that $\mathrm{R} \& \mathrm{D}$ of students complied with most criteria, except for requirement to statistic data processing. However, insufficient fulfillment of parameters was observed related with foreign languages and dominating nonconformance of parameter of statistic data processing due to unavailable database for sufficient representative selection. Therefore, further work with students is possible concerning improvement of these parameters, which is planned for future graduate courses. 


\section{References}

1. J. Kirton, B. Warren, Bulletin of International Organizations 13(2), 17-47 (2018)

2. L.A. Vidyasova, A.V. Chugunov, E.Yu. Vidyasov, Bulletin of international organizations: education, science, new economy 12(1) 66-80, (2017)

3. K.K. Golubushina, I.A. Vinogradova, O.I. Klyuchko, E.V. Samosadova, Higher education in Russia 5, 103-110 (2015)

4. A.M. Alenezi, Science and education 22(4), 89-109 (2020)

5. S.N. Vachkova, Social Psychology and Society 5(4), 135-144, (2014)

6. M.V. Voropaev, A.N. Ganicheva, A.P. Kaitov, A.S., Lvova, O.A. Lyubchenko, E.K. Nikitina, O.A. Polezhaeva, Yu.A. Serebrennikova, S.Yu. Stepanov, Virtual Cluster (Moscow, 2019)

7. M. Janelli, Education Issues 4, 81-98 (2018)

8. V.A. Yasvin, European Journal of Contemporary Education 1(1), 82-92 (2012)

9. A.D. Rybkin, V.M. Grebennikova, European Journal of Contemporary Education 8(2), 348-356, (2019)

10. A.L. Sotnikova, B.B. Yarmakhov, E.D. Patarakin, Psychological science and education 23(3), 67-76 (2018)

11. A.I. Savenkov, S.I. Karpova, E.I. Sukhova, Psychology (Savannah, Ga.) 55(2), 74-84 (2018)

12. A.Yu. Fedosov, N.P. Khodakova, Yu.A. Brevnova, A.A. Ziroyan. G.S. Sulyan, Amazonia Investiga 7(12), 579-584 (2018)

13. R.A. Kutbiddinova, A.A. Eromasova, M.A. Romanova, International Journal of Environmental and Science Education 11(14), 6557-6572 (2016)

14. M.G. Sorokova, Psychological science and education 25(1), 36-50 (2020)

15. S. Vorovshchikov, E. Artamonova, C. Speshneva, A. Sabiyeva, R. Urazalieva, Espacios 40(12), 25 (2019)

16. I. Froumin, I. Remorenko, From the "best-in-the world" soviet school to a modern globally competitive school system, in Audacious Education Purposes. How Governments Transform the Goals of Education Systems Collected articles (Cambridge, 2020).

17. Sh.A. Amonashvili, I.I. Zaitseva, Education and self-development 5(33), 28-32 (2012).

18. E.E. Kabanova, E.A. Vetrova, European Journal of Contemporary Education 8(3), 524533 (2019)

19. A.V. Kudryashova, Ya.V. Rozanova, T.V. Sidorenko, Science and education 22(4), 131145 (2020) 